\title{
Quality of service analysis of GSM telephone system in Nigeria
}

\author{
${ }^{1 *}$ Adegoke A.S and ${ }^{2}$ Babalola I.T
}

\author{
${ }^{1}$ Dept of Engineering, University of Leicester, Leicester LE1 7RH, United Kingdom. \\ ${ }^{2}$ Dept of Electrical Engineering, Yaba College of Technology, Yaba, Lagos Nigeria \\ *Correspondence E-mail:- adegokeas2000@yahoo.com
}

\begin{abstract}
Quality of service is an important key performance indicator (KPI) that is used in determining the efficiency of an industry in terms of services rendered. In telecommunication system, accessibility, retainability and connection (voice) quality are three major factors used in evaluating quality of service of an operator. And for consumers in the industry, it is expected that maximum satisfaction be derived from any services paid for. This (maximum satisfaction) has now become a difficult task to achieve especially in GSM industry. One of the major reasons attributable to this is as a result of mismatch between expansion in customer base and infrastructural (Network) expansion. This paper has therefore appraised the performance of GSM operators in Nigeria and examined the problems facing the industry. Also, methods for improvements were suggested.
\end{abstract}

Keywords:- Network accessibility, call drop, efficiency, congestion

\section{INTRODUCTION}

Ten years ago, Nigeria embraced the global system for mobile communication (GSM). Its adoption is expected to serve as a viable alternative to the then analog (Nitel) system. Also, during its launching in 2001, the core objective is to provide effective telecommunication services that will support good speech quality, roaming, spectral efficiency, minimized crosstalk, etc. The deployment of GSM system into Nigerian market was universally embraced and found to be relatively efficient at the inception. With time, operators in the industry experienced an unprecedented growth in customer base which later incapacitated the networks to function efficiently.

Although, this explosive growth has brought huge revenue to both the operators and government through tax and license fee. As revolutionary as GSM may seems to be, many problems bedevil the sector in recent past. Some of the problems are:-

* Instability in power supply

* Security of infrastructure

* Inter-Network connectivity

* Network congestion

* Call setup failure

* Call retention / call drop

All these factors contribute in one way or the other to the poor quality of services rendered by GSM operators in the country.
Worried by the spate of development in the industry, the nation's lawmakers (upper legislative house) in year 2007 set up a committee to investigate the inefficiency of the service providers. While this was going on, the house of representative on July 18 , 2007 invited the service providers to appear before its adhoc committee mandated to investigate the activities of the service providers. They maintained that this became necessary due to public outcry on the epileptic services, as well as its economic and social implications. The NCC on their part made a statement recently (on $11^{\text {th }}$ Feb. 2009) by their CEO at a public forum on QoS issue, he said " our focus for 2009 is to administer and monitor closely a performance management program to ensure that operating companies maintain minimum performance levels jointly agreed between the GSM operators, consumer representatives and NCC and, in consistent with the world class standards". At this forum, the commission outlined a benchmark of QoS indicators in form of technical parameters that must be followed by all operators. This, according to NCC will be closely monitored and evaluated on quarterly basis while stiff penalties were also spelt out for any erring operators for non-compliance.

\section{HISTORICAL BACKGROUND}

The idea of cell - based mobile radio system was first conceived at Bell laboratories in (USA) in the early1970s. However, mobile cellular systems were not introduced for commercial use until the 1980s. During this 1980s, analog cellular telephone systems 
experienced a very rapid growth in Europe, particularly in Scandinavia and in United Kingdom. But in the beginning of Cellular system, each country developed its own system which was an undesirable situation for the following reasons;

* The equipment was limited to operate only within the boundaries of each country

* The market for each mobile equipment was limited

In order to overcome these problems, the Conference of European Posts and Telecommunications (CEPT) in 1982, formed the Groupe Special Mobile (GSM) in order to develop a pan-European mobile cellular radio system (with this, GSM acronym became global system for mobile communication). This group came up with a digital system that has to meet the following criteria.

* Spectrum efficiency

* Good subjective voice quality

* International roaming

* Compatibility with other systems such as ISDN

* Low Mobile and base stations cost

A digital system was adopted by the group (CEPT) as opposed to the then analog cellular systems like AMPS in the United States and TACS in the United Kingdom. The reason for this is on the aspect of quality of service. For example, analog system do pass physical disturbance in radio transmission to the receiver. These disturbances do decrease signal quality because they produce effects such as fadeouts, crosstalk, hisses etc. On the other hand, digital systems avoid these effects. The phase 1 of the GSM specifications was published in 1990. Commercial services started mid- 1991, and by 1993 there were 36 GSM networks in 22 countries. By the beginning of 1994, there were 1.3 million subscribers world wide, which grew to 55 million by October 1997.

\section{Factors affecting service efficiency: \\ * Instability in Power Supply \\ * Security of Infrastructure \\ * Call setup failure \\ * Call retention / call drop \\ * Congestion}

\section{INSTABILITY IN POWER SUPPLY}

Recent study revealed that $78 \%$ of the total cost of operations by GSM operators goes into provision of generators and its fueling. The epileptic nature of our power supply system in the country had necessitated the over-dependence on generators. The direct implication of this is that call tariff will drastically shoot up. Apart from this, it is obvious that the cost of procurement and fueling is so enormous. If our power supply system is stable, this huge amount could have been used in upgrading and optimizing existing base stations in order to improve service efficiency. Also, additional base stations and switching centres could be built with it for network expansion which will eventually alleviate congestion and the network will have capacity to handle more calls.

So, the bad network experienced in the country can not be completely divorced from instability in power supply.

Security of infrastructure: Due to the volatile nature of some parts of the country, telecommunication equipments are not safe from vandalisation. There have been many reported cases of theft and vandalisation at base station sites. This development has prompted telecoms operators to invest heavily on recruitment of security personnel at their base station sites. One direct implication of this is that the cost incurred on these security guards goes into the total cost of operation and subsequently leading to increase in call tariff.

However, the presence of the security guards at the base stations has not totally prevented armed robbers, thugs and hoodlums from vandalizing and carting away generators and valuable equipments at base station sites. In addition, some base stations have been shut down due to these nefarious activities. The technical implication of this is that once a base station is shut down, call transmission for subscribers in that location would automatically be transferred to another nearby base station which will lead to network congestion. Subsequently subscribers within this area will experience poor quality of service.

Call set up failure: This is an important parameter used in determining network accessibility. It is the ability of a subscriber to initiate a call and granted access. Technically, during a GSM call setup, a speech call is assigned from a SDCCH (stand alone dedicated channel) to a $\mathrm{TCH}$ (traffic channel). If the $\mathrm{TCH}$ selected suffers from interference, then the assignment will fail. And the assignment failure message will be sent to the MSC. The call will then be re-established back.

According to the earlier survey carried out by NCC, all the three major operators were found to perform 
poorly in the area of number of time that users dial before connection is made. The survey shows that only less than half of the subscribers on each of the networks do get their calls through on the first or $2^{\text {nd }}$ dial. (Airtel - 49\%, MTN - 46\% GLO - 47\%). In other words, subscribers who dial 3 -times or more were (Airtel - 49\%, Glo - 50\% MTN - 50\%). Result of sampled opinion is as shown in tables and figures:

Table 1 Table showing subscribers dialing 3 or more times before getting connected

\begin{tabular}{|l|l|l|l|}
\hline CITY & AIRTEL \% & $\begin{array}{l}\text { MTN } \\
\mathbf{\%}\end{array}$ & $\begin{array}{l}\text { GLO } \\
\mathbf{\%}\end{array}$ \\
\hline Abuja & 56 & 63 & 67 \\
\hline Kaduna and Zaria & 39 & 50 & 45 \\
\hline Kano & 61 & 53 & 39 \\
\hline Maiduguri & 41 & 42 & 53 \\
\hline Jos & 33 & 38 & 48 \\
\hline Bauchi & 57 & 68 & 49 \\
\hline Ibadan & 46 & 41 & 42 \\
\hline Calabar & 45 & 79 & 50 \\
\hline Port-harcourt & 44 & 47 & 20 \\
\hline Owerri & 63 & 54 & 45 \\
\hline Enugu & 37 & 59 & 61 \\
\hline Benin & 51 & 60 & 58 \\
\hline Lagos & 35 & 39 & 50 \\
\hline Kwara & 46 & 36 & 33 \\
\hline
\end{tabular}

AGGREGATE, AIRTEL $=47 \%$, MTN $=50 \%$, GLO $=$ $49 \%$

Table 2.0 showing subscribers connected to numbers not dialed

\begin{tabular}{|l|l|l|l|}
\hline CITY & $\begin{array}{l}\text { AIRTEL } \\
\%\end{array}$ & $\begin{array}{l}\text { MTN } \\
\%\end{array}$ & $\begin{array}{l}\text { GLO } \\
\%\end{array}$ \\
\hline Abuja & 38 & 35 & 27 \\
\hline Kaduna and Zaria & 41 & 36 & 28 \\
\hline Kano & 39 & 42 & 35 \\
\hline Maiduguri & 69 & 68 & 54 \\
\hline Jos & 46 & 29 & 34 \\
\hline Bauchi & 19 & 60 & 31 \\
\hline Ibadan & 15 & 27 & 22 \\
\hline Calabar & 15 & 14 & 20 \\
\hline Owerri & 33 & 31 & 41 \\
\hline Enugu & 19 & 33 & 13 \\
\hline Benin & 22 & 51 & 23 \\
\hline Lagos & 31 & 27 & 22 \\
\hline Kwara & 40 & 25 & 32 \\
\hline AGGREGATE, AIRTE & & & \\
\hline
\end{tabular}

AGGREGATE, AIRTEL = 34\% MTN = 32\% GLO = 28\%

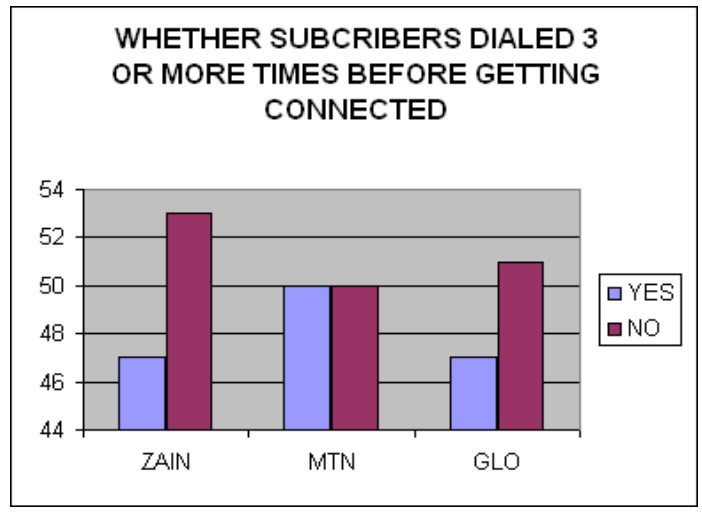

Fig. 1.0

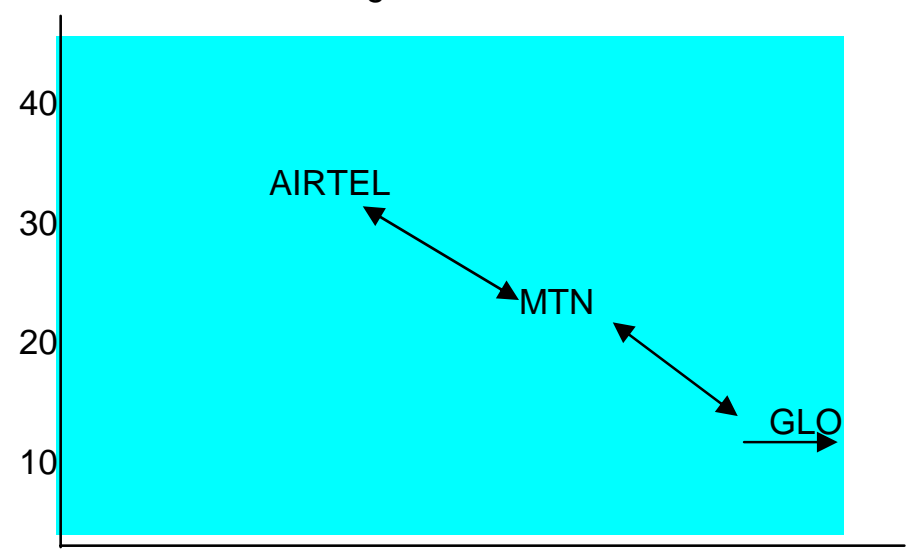

Fig 2.0: Subscriber dialing 1-2 times before getting connected

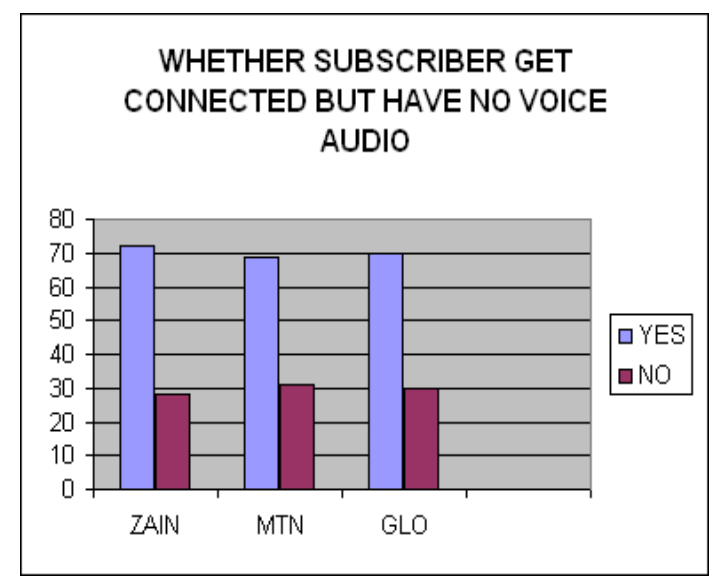

Fig. 3.0

Call retention / call drop: Call retention is the ability to retain a GSM call after it has been established while dropped call is a situation whereby an established call is abruptly terminated while conversation is ongoing. It is a common occurrence 
in Nigeria's GSM system that communication is terminated unexpectedly while conversation is ongoing. This is technically called Call Drop. Reasons for dropped calls are as listed below:-

- Calls may be dropped when the mobile phone moves out of coverage area. Once the signal strength between the mobile equipment (ME) and the network cannot be sustained, the call will be terminated.

- Calls may be lost due to path loss or shadowing. For instance, in typical GSM system, Transmit power is $+43 d B$ and receiving power ranges between $-60 \mathrm{~dB}$ to $85 \mathrm{~dB}$. If due to pathloss, the receiver signal strength drops to $-95 \mathrm{~dB}$, that call will drop.

- Battery power loss:- Calls may be lost if a mobile phone at the other end of the call losses battery power and stops transmitting abruptly.

- $\quad$ Calls may be dropped upon handoff between cells within the same provider's network. This may be due to an imbalance of traffic between the two cell site's areas of coverage. If the new cell site is at capacity, it will not be able to accept additional traffic of the call trying to "hand-in". it may also be due to the network configuration not being set up properly, such that one cell is not aware of the cell the phone is trying to hand off to.

A survey conducted by NCC recently clearly showed that one of the most important customer perceived problems that affects quality of service is in the area of dropped calls. This is as depicted ion Table 3.0 below

Table 3.0 Summary of Dropped calls and their locations

\begin{tabular}{|l|l|l|l|}
\hline CITY & AIRTEL\% & MTN\% & GLO\% \\
\hline Abuja & 67 & 69 & 60 \\
\hline $\begin{array}{l}\text { Kaduna and } \\
\text { Zaria }\end{array}$ & 29 & 67 & 59 \\
\hline Kano & 74 & 77 & 73 \\
\hline Maiduguri & 47 & 34 & 34 \\
\hline Jos & 57 & 64 & 74 \\
\hline Bauchi & 32 & 36 & 58 \\
\hline Calabar & 65 & 59 & 75 \\
\hline Owerri & 52 & 62 & 51 \\
\hline Enugu & 69 & 57 & 60 \\
\hline Benin & 62 & 71 & 70 \\
\hline $\begin{array}{l}\text { Port- } \\
\text { Harcourt }\end{array}$ & 84 & 78 & 79 \\
\hline AGGREGATE; AIRTEL & & \\
\hline
\end{tabular}

AGGREGATE; AIRTEL 64\%, MTN 67\%, GLO 64\%
As shown in table 3.0 above, dropped calls are more prominent in port-Harcourt than in any other place with a complaint level of over $78 \%$. On the other hand, Maiduguri experienced less dropped calls with a complaint level of over $42 \%$ on aggregate compared to most other parts of Nigeria.

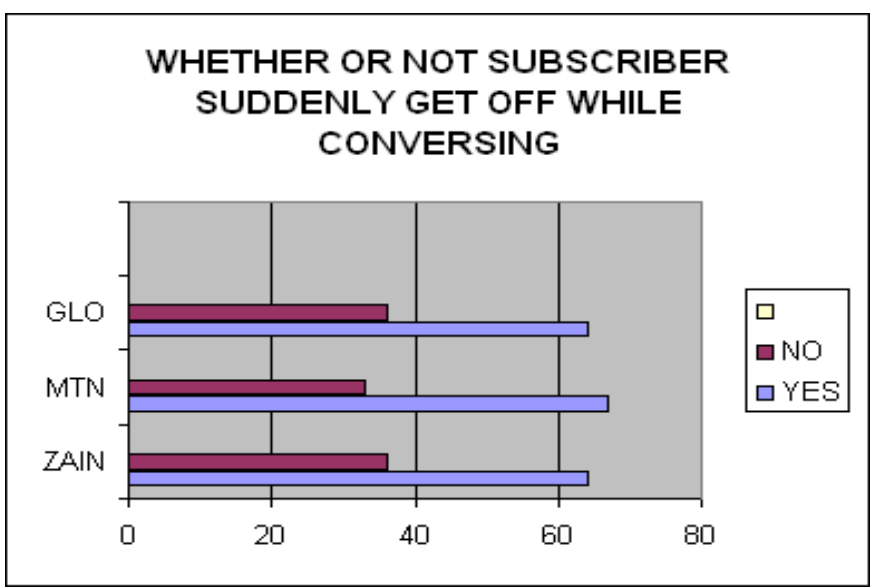

Fig. 4.0

Congestion: Congestion is a phenomenon in telecommunication system that occurs when more subscribers attempt simultaneously to access the network than it is able to handle. This is a situation where subscriber numbers has completely overgrown network capacity. Reasons for network congestion are

- Lack Of Adequate Infrastructures:- To guarantee efficient network Quality, there must be adequate infrastructural equipments to be able to drive the network. Also, the size of these equipments must be in tandem with the subscriber's base. When subscriber's base overgrows infrastructural equipment, then congestion is inevitable. In Nigerian situation, operators have been playing down on expansion of all cell sites, which of course is the strength of call quality. The rate of service rollout in the country has never been the same with the rate of infrastructural rollout, and this often leads to Network Congestion and inability to recharge phones.

- Insufficient Channels:- Since there are not enough infrastructural equipments (e.g. base stations), automatically there will be lack of adequate channels to support network functionality. Recall that channels are normally used to determine total number of 
subscribers that can be allowed to use a base station.

The Nigerian Communication Commission (NCC) had long ago, noticed the gap between infrastructure rollout and Subscriber's growth, a situation that compelled the commission to place ban on promos in year $2007 \& 2008$. it later rescinded its decision in year 2009 on promo ban and went into monthly testing of call quality across network. In one of the results released recently, subscriber's population across all networks as at 2008 was 64 million. But this has grown up to 70 million this year (2009) for both GSM and CDMA. The graphical picture of subscriber' growth between 1999 to 2008 is as shown in Fig. 5.0 below.

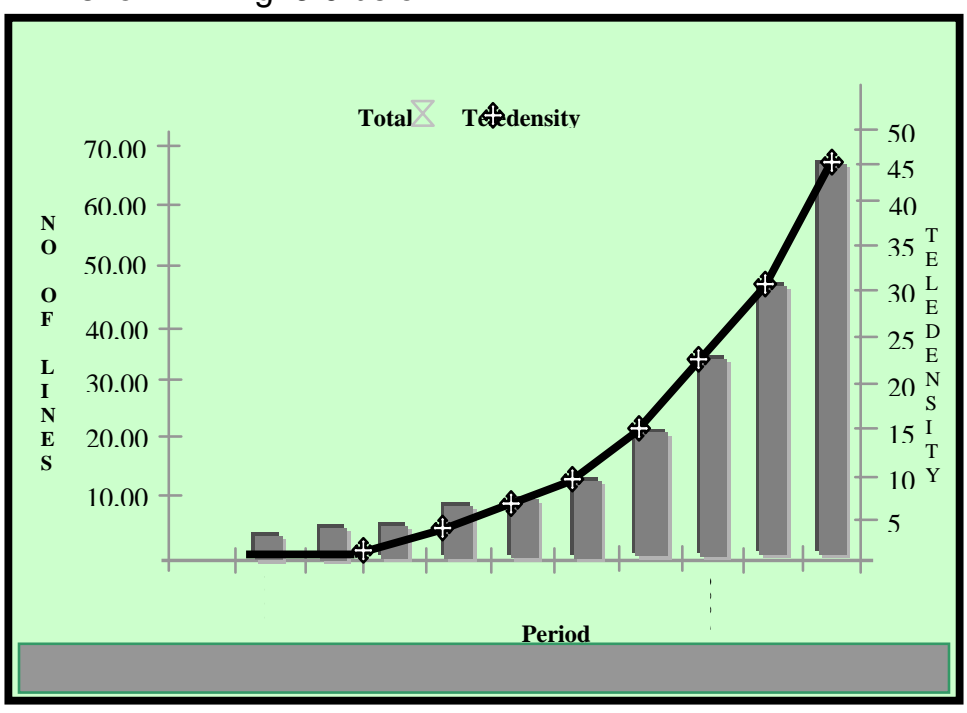

Fig. 5 Subscribers’ Data (1999 - 2008)

Worried by this spate of development on Congestion analysis, the then Executive Vice Chairman of NCC stated recently that "unless operators are able to roll out 40,000 base stations across the country, which is the projected target by the end of 2010, operators will continue to experience network congestion". He also decried the present number of base stations in the country, which he puts at 14,000 for GSM and 2,400 for CDMA operators

Suggested methods of improvement: Having evaluated the parameters that attributed to poor quality of service by operators, the following under listed methods are suggested towards improving network performance.

1. Operators should upgrade and optimize all existing base stations. If this is done, it will stem call set up failures due to rise in traffic volumes.

2. Install additional base stations across the country. This would create room for the network to handle more traffic.

3. Build additional switching centers across the country and increase capacity to handle more traffic.

4. If a particular base station is to be taken "offline" (either for schedule maintenance, repairs, upgrades etc.), all neighbouring base stations should have their communication power level increased. This will increase their coverage area, thereby reducing congestion and dropped calls.

5. Operators should invest heavily in transmission network development and have a proper radio planning. This would ensure increased network resilience, improved bandwidth utilization and alleviation of capacity bottleneck.

6. Operators should continue to give back to the society aimed at enhancing social security. Because no amount of security personnel can deter hoodlums from attacking base station sites. Also, if government can create more jobs for its citizens, poverty level would be reduced and a lot of boys and girls will be taken off streets. Hence we would have a secured environment.

7. Incessant power failures should be addressed by the government. This will stop the over-dependence on generators for power supply. If this is achieved, call tariff would drastically go down.

\section{DISCUSSION}

As can be seen in our presentation, the report reflects the experiences of subscribers as they perceived quality of service offered to them by their respective providers. In general, all the networks performed fairly well in dialing few times before getting call and getting connections to the number dialed. But did poorly in cutting off while conversing (dropped call) and worse in connections without voice audio. Though, the situation of each network might have changed subsequently, but the present result indicates that the performance of GSM networks in Nigeria is still a far cry from expectations of the consumers. And urgent improvement is needed in specific locations where comparatively large proportions of subscribers have complained. 


\section{CONCLUSION}

Network performance is the most important parameter for measurement of quality of service. Poor performance of a telecom network would induce customer complaints and faults, thereby leading to customer dissatisfaction towards the operator. It is evident from this presentation that the quality of service rendered by these operators is far below expectation. So, urgent and proactive actions should be taken by the operators towards improving network performance. If this is done, customers could enjoy the best quality of service in terms of call success rate, voice quality network availability etc.

\section{REFERENCES}

\{1\} Adegoke A.S, I.T Babalola and W.A Balogun, 2008. "Performance evaluation of GSM mobile system in
Nigeria". Pacific Journal of Sc. \& Tech. Vol. 9, No 2, Nov. 2008.

$\{2\}$ www.on-qtelecom.com

\{2\} www.techrepublic.com

\{3\} www.mobileafrica.net

\{4\} Sola Fanawopo, GSM operatos employ 18,000 security operatives to guard base stations Daily sun Newspaper, Oct 10 2007, pp 27.

\{5\} David Aduge-Ani, "sorry The Network is not available" Nigerian Newsworld magazine. August $6^{\text {th }} 2007$, pp 5052

\{6\} N.C.C., "A quality of service performance of survey of GSM providers in Nigeria Computer.com/the ICT newspaper, February 2006 pp 22-25 